\title{
ABDOMINAL COMPARTMENT SYNDROME IN POLYTRAUMA
}

\author{
Leopold Pleva a , Milan Š́r, Jaroslav Mayzlík ${ }^{\mathrm{b}}$ \\ a Centre of Traumatology, University Hospital Ostrava, Czech Republic \\ ${ }^{b}$ Clinic of Surgery University Hospital Ostrava
}

Received: March 25, 2004; Accepted: May 26, 2004

Key words: Blunt abdominal trauma/Abdominal compartment syndrome/Intraabdominal pressure/Laparostomy

Authors inform about the group of 8 patients with abdominal compartment syndrome (ACS) occurred as a complication in large blunt injury of abdominal cavity. To the ACS diagnose, the measurement of intracystic pressure is used routinely, whose values correlate fully with values of intraabdominal pressure (IAP). In case of increasing values of IAP over $25 \mathrm{~mm} \mathrm{Hg}$ with positive clinical signs of ACS, authors indicate decompression laparotomy with temporary closing of abdominal cavity by sterile plastic foil or Ethizip. This preventive temporary laparostomy is recommended also in serious injuries of abdominal cavity in patients with fatal haemorrhage, treated by the method of staged laparotomy with tamponade of abdominal cavity and with massive blood and volume resuscitation.

\section{INTRODUCTION}

Abdominal compartment syndrome (ACS) develops on the basis of increased intraabdominal pressure (IAP), with its pathophysiological consequences manifesting all over the organism. After injuries, mostly in case of serious abdominal injuries with massive intraabdominal and retroperitoneal bleeding in abdominal cavity due to coagulopathy, or in tamponade of non-surgical bleeding in abdominal, pelvic or retroperitoneal space, or accumulation of blood coagula, but also in case of edema and leak of intestinal wall from massive volume resuscitation and perfusion or in case of tension closure of the abdominal cavity. ACS however develops also after protracted abdominal cavity operations. Clinical picture of developed ACS was probably defined best by Ivatury in 1997, characterizing the abdominal distension, hypoxia and hypercapnia with oliguria up to anuria, when this organ dysfunction is adjusted only after performing the abdominal decompression? .

With regard to the fact that abdominal compartment syndrome mostly shows in polytraumatised patients in critical condition it is complex to diagnose it, but it is not difficult because the application of method of measuring the intracystic pressure in the urinary bladder, which is a simple and miniinvasive method, allows for monitoring the intraabdominal hypertension that fully corresponds with the intracystic pressure values. Normal values of intraabdominal pressure range from $0-5 \mathrm{mmHg}$. Slightly increased values are reported ranging from 10 to 15 $\mathrm{mmHg}$, when the heart index is usually maintained and renal symptoms do not appear. However, with mediumincreased values of $15-25 \mathrm{mmHg}$ full abdominal compartment symptom may already develop and if the organism fails to respond to aggressive supply of fluids to the blood circulation with temporary use of vasoconstriction means, it is recommended to carry out the decompression operation of abdominal cavity, which is fully indicated with IAP exceeding $25 \mathrm{mmHg}\left(\right.$ ref. $\left.^{2}\right)$.

\section{METHODOLOGY AND PATIENTS}

From 1999 to 2002, 436 polytrauma patients were treated at the Traumatological Centre of the University Hospital in Ostrava. Traffic accident trauma prevailed in $73 \%$ together with sporting and leisure time injuries. There were 87 abdominal cavity trauma, in this 31 injuries of liver, 35 injuries of spleen, 4 injuries of pancreas, 12 injuries of bowels and 5 injuries of retroperitoneum.

Abdominal compartment syndrome occurred in 8 patients, 6 times in liver injury, treated by suture and drainage in 4 cases and by tamponade in the area of traumatised liver segment 7 and 8 in two cases. In another patient, ACS developed in blunt abdominal trauma associated with pelvic fracture, where decompression laparotomy found no surgical source of bleeding and there was only $500 \mathrm{ml}$ of blood in the Douglas space, but extensive distension of thin loops was found together with edema thereof. The abdominal cavity was closed after exploration without tension using the Ethizip (Fig. 1) and a definite closure was made on the $9^{\text {th }}$ post-operation day. Immediately after decompression of the abdominal cavity, diuresis was restored and ventilation parameters of the injured improved significantly. In the last patient, ACS developed due to extensive retroperitoneal hematoma with injury of soft retroperitoneal issues and pelvic fracture, where progressive bleeding into abdominal cavity occurred with developed coagulopathy. 


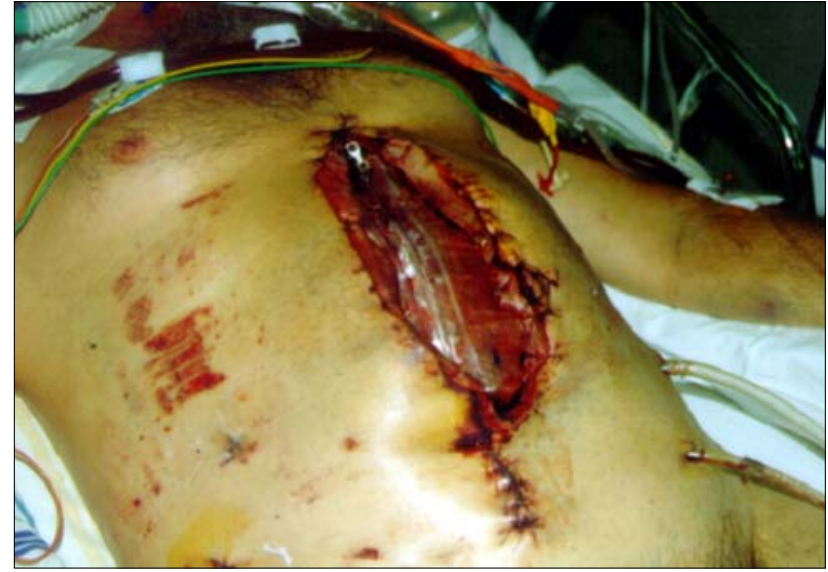

Fig. 1.

On decompression laparotomy, $1500 \mathrm{ml}$ of blood was found coming from the retroperitoneal space, where revision found no surgical source of bleeding; therefore, retroperitoneal tamponade was carried out and the laparotomy was closed by plastic foil (Fig. 2). The tamponade was removed after 24 hours with definite closure of abdominal cavity in 7 days. The patient was dismissed for home treatment on $21^{\text {st }}$ day.

In our clinical set, two ACS patients died, one after multi-organ failure in sepsis due to extensive trauma of liver and spleen, and one due to craniotrauma after decompression craniotomy with malignant brains edema.

\section{DISCUSSION}

Abdominal compartment syndrome has been indicated as a complication in serious abdominal trauma for more than 50 years. It develops as a consequence of increased intraabdominal pressure not only in abdominal trauma, but also in intestinal obstructions with serous edema of the bowels or a chronically growing ascitus, in acute haemorrhagic necrotic pancreatitis and septic peritonitis. In recent years, its occurrence has been reported

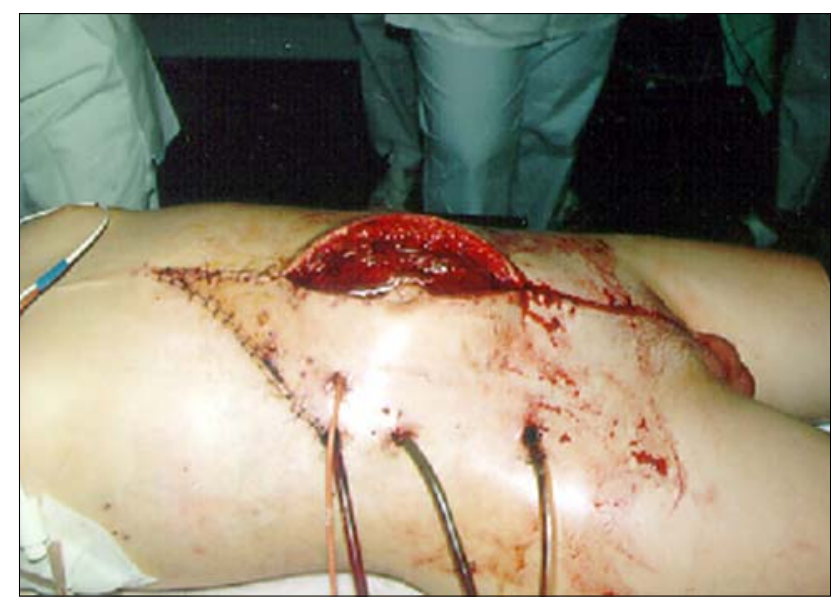

Fig. 3.

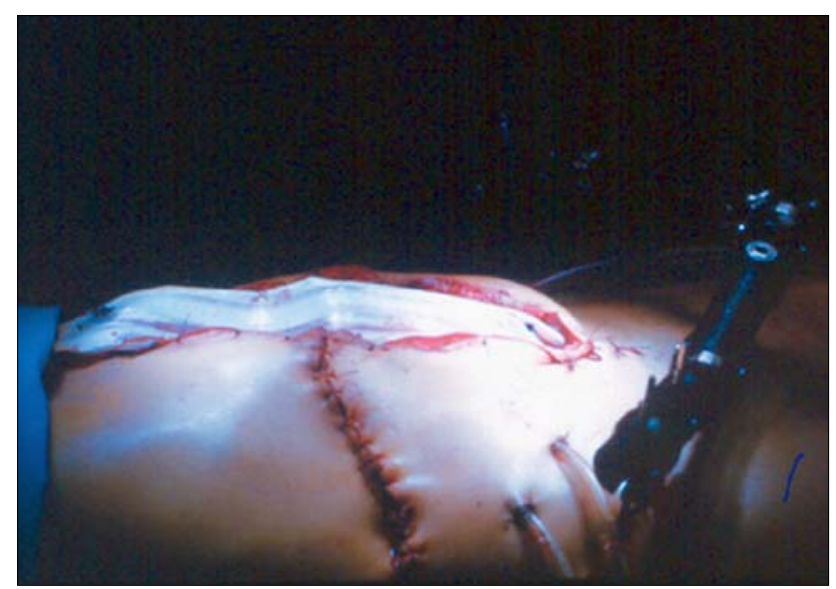

Fig. 2.

also in protracted operations in the abdominal cavity with subsequent extensive resuscitation ${ }^{10}$.

The increase in intraabdominal pressure is, however, also caused by increased abdo-minal content on tamponade of non-surgical bleeding in abdominal, pelvic and retroperitoneal area, accumulation of blood coagula, or possibly continued bleeding in abdominal cavity on coagulopathy or on intestinal distension after injury of mesenterial vessels and last but not least, also upon closure of abdominal cavity under tension ${ }^{11}$. Progressively growing intraabdominal hypertension always negatively affects the function of adjacent and distant organs, showing itself in the cardiovascular system as decreased minute cardiac volume as a consequence of increased vascular resistance with decreased venous return ${ }^{20}$, which manifests as increased intrathoracic pressure with ventilation and perfusion changes, hypoventilation, hypoxia and hypercapnia, and decreased pulmonary compliance ${ }^{19}$, the resulting condition of which is restriction respiratory syndrome. Renal dysfunction is manifested as oliguria up to anuria as a consequence of decreased perfusion of retroperitoneal, and also intraabdominal organs, when the splanchnic ischemia affects not only the liver metabolism ${ }^{6}$, but allows also for translocation of endotoxins and bacteria through ischemized intestinal mucous barrier, which allows for

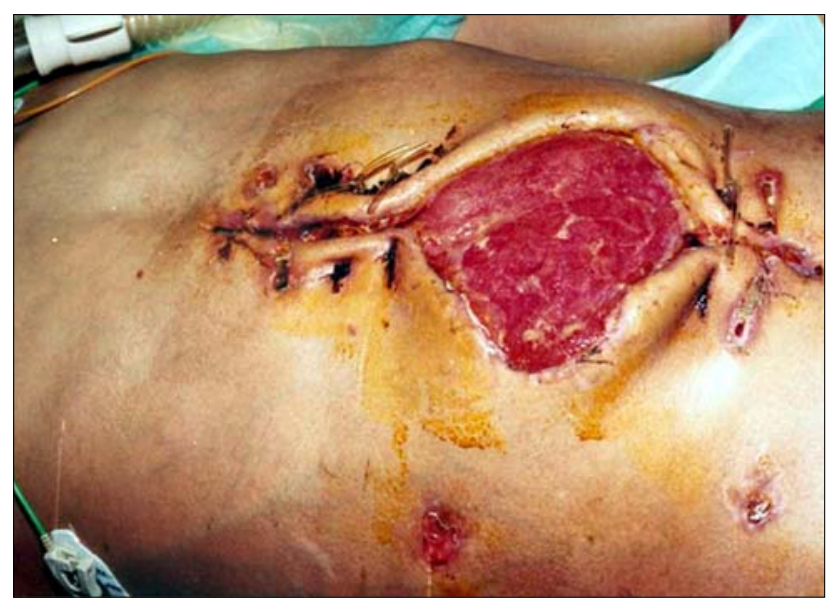

Fig. 4. 


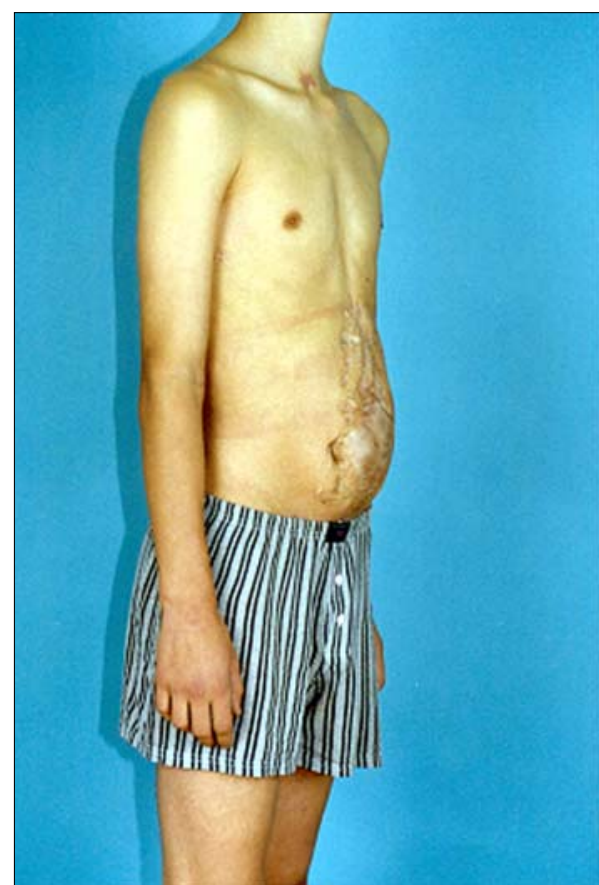

Fig. 5.

activation of septic syndrome trigger factor ${ }^{5}$. Intraabdominal hypertension further causes also the increase of intracranial pressure ${ }^{2}$ with danger of ischemic neural damage with decrease of cerebral perfusion pressure. All symptoms of these organ dysfunctions are caused by acute increase of intraabdominal pressure with consequences of abdominal compartment syndrome.

One clinical picture of ACS is characterised by abdominal distension, hypoxia and hypercapnia with oliguria up to anuria, when organ dysfunction improves after abdominal decompression. Persisting increase in intraabdominal pressure over $25 \mathrm{mmHg}$ with clinical symptoms of ACS are indications for decompression operation of abdominal cavity.

During decompression operation, blood, blood coagula and secreta are removed from the abdominal cavity. In the event of continued non-surgical bleeding a tamponade is applied, which is subsequently renewed, or the bleeding is treated surgically (wiring, punch) and the abdominal cavity is flushed with warm saline ${ }^{10}$. Laparotomy or relapatotomy is closed by means of synthetic material - absorbable, non-absorbable mesh, plastic foil (Fig. 3) and in recent year also Ethizip.

At every next revision of the abdominal cavity the foil incision or release of Ethizip is sufficient. In ideal case, we can definitely close the abdominal revision after the last revision. In the event of persisting defect of abdominal wall, ventral hernia may develop, which will be treated in the second period (Fig. 4-6).

However, during or immediately after decompression laparotomy symptoms of reperfusion syndrome may develop in come patients, resulting even in asystolia caused, according to some authors, by sudden decrease

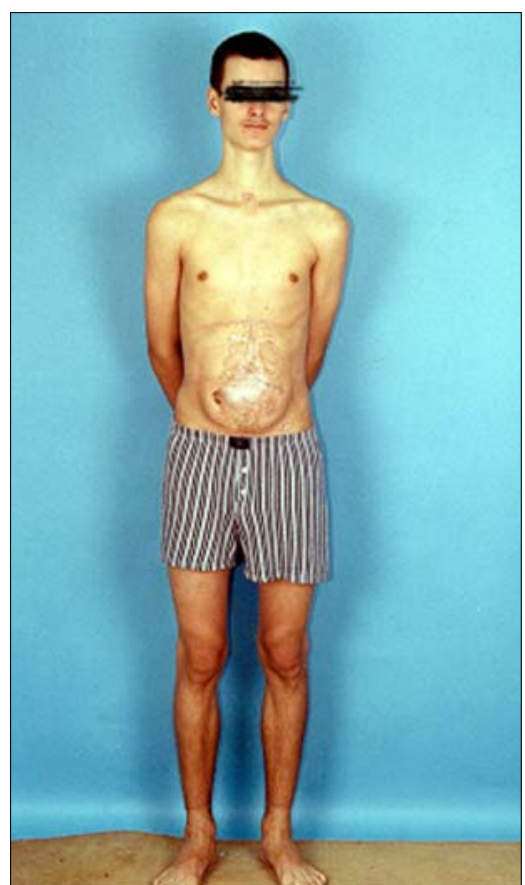

Fig. 6.

in systemic vascular resistance with subsequent serious hypovolemia ${ }^{13}$ or perfusion of anaerobic metabolism products from splanchnic area. To prevent this complication, volume preliminary filling of the circulation is recommended by application of 21 of saline with Manitol and bicarbonate applied immediately before decompression of abdominal cavity ${ }^{8}$.

In recent years, the literature has mentioned also procedures to prevent ACS development, for which the patient endangered by ACS has been defined. It is an "abdominal catastrophe" patient in danger of bleeding to death, treated by staged laparotomy method, often with tamponade, who has received a large number of blood transfers with significant volume therapy.

In these patients it is recommended to perform preventive closure of primary laparotomy using meshes or plastic foils, which successfully prevents from development of $\mathrm{ACS}^{13}$. Primary laparotomy closed with mesh or foil or Ethizip, as appropriate, allows for faster abdominal cavity decompression in the event of increasing IAP event in the ICU room, which prevents from further risk of complications occurring during transport of the patient to the operating room, which relates to the necessary ventilation support as most transport ventilators do not achieve the necessary efficiency to maintain the adequate respiratory volume in the event of increased respiratory pressures $^{8}$. However, it is still impossible to specify fixed uniform criteria for preventive use of temporary closure of abdominal cavity using the mesh or foil, because it will always depend on subjective assessment of the operator regarding the tension of abdominal cavity after proximation of the fascia edges and estimation of the amount by which the content of abdominal cavity may increase or has already increased during tamponade. 
Further, however, there is a question whether it is not more advantageous in hazard patient to carry out the primary closure of abdominal cavity with post-operation IAP monitoring and early ACS diagnostics instead of preventive temporary laparostomy.

\section{CONCLUSION}

Abdominal compartment syndrome is a serious multidiscipline issue of urgent surgery, which the physicians must always be aware of in case of any serious abdominal cavity trauma connected with massive bleeding, but also in case of any protracted operation with massive volume resuscitation including early post-operation periods. In the event of any suspicion for acute elevation of intraabdominal pressure in these patients it is essential to measure the intracystic pressure continuously, and in the event of clinical symptoms of acute abdominal compartment syndrome with increase in intracystic pressure over 25 $\mathrm{mmHg}$ the performance of decompression laparotomy is indicated even with the assumption of negative peroperation finding, with temporary closure of the abdominal cavity with sterile foil or Ethizip. There should be no indication hesitation to perform the laparotomy even though abnormal coagulation parameters occur, because the acute decompression laparotomy reduces IAP and will allow for tamponade with better compression of the bleeding surface, or it may discover major bleeding, which can be treated surgically, but first of all it will improve the mucous perfusion with acidosis reduction. Therefore, acute decompression or reexploration of the abdominal cavity is fully indicated in case of progressive growth of IAP or event abnormal coagulation parameter ${ }^{10}$.

\section{REFERENCES}

1. Backer D. (1999) Abdominal compartment syndrome. Crit Care 3, 103-104.

2. Bloomfeld GL, Dalton JM, Sugerman HJ et al. (1995) Treatment of increasing intracranial pressure secondary to the acute abdominal compartment syndrome in patient with combined abdominal and head trauma. J Trauma 39, 1168-1170.
3. Carry PY. (1994) La pression intra-abdominal. Ann Fr Anesth Reanim 13, 381-389.

4. Cullen DJ, Coyle JP, Teplick R et al. (1989) Cardiovascular, pulmonary and renal effects of massively increased intra-abdominal pressure in critically ill patients. Crit Care Med 17, 118-121.

5. Diebel LN, Dulchavsky SA, Wilson RF. (1992) Effect of increased intra-abdominal pressure on mesenteric arterial and intestinal mucosal blood flow. J Trauma 33, 45-49.

6. Diebel LN, Wilson RF, Dulchavsky SA et al. (1992) Effect of increased intra-abdominal pressure on hepatic arterial, portal venous, and hepatic microcirculatory blood flow. J Trauma 33, 279-282.

7. Diebel LN, Wilson RF, Dulchavsky SA. (1992) Effect of intraabdominal pressure on abdominal wall blood flow. Am surg 58, 573-575.

8. Eddy V, Nunn C, Morris JA. (1997) Abdominal compartment syndrome. Surg Clin Am 77, 801-812.

9. Ivatury RR, Diebel L, Porter JM et al. (1997) Intra-abdominal hypertension and the abdominal compartment syndrome. Surg Clin Am 77, 783-800.

10. Ivatury RR, Poter JM, Simon RJ et al. (1998) Intra-abdominal hypertension after life-threatening penetrating abdominal trauma: prophylaxis, incidence, and clinical relevance to gastric mucosal $\mathrm{pH}$ and abdominal compartment syndrome. J Trauma 44, 10161021.

11. Ivatury RR, Simon J. (1996) Intra-abdominla hypertension: the abdominal compartment syndrome. Crit Care 73, 951.

12. Ivatury RR, Schein M. (1998) Intraabdominal hypertension and the abdominal compartment syndrome. Br J Surg 85, 1027-1028.

13. Kitka M, Pleva L. Poranenia orgánov brušnej dutiny. Košice: Klinika úrazovej chirurgie LF UPJŠ a FNLP, 2003. 1. vyd. 73.

14. Kron IL, Harmann PK, Nolan SP. (1984) The Measurement of Intra-abdominal Pressure as a Criterion for Abdominal Re-exploration. Ann Surg 1999, 28-30.

15. Mašek M, Žák J, Chalupník Š, Šrámek V. (1999) Nejčastější chyby v měření nitrobřišního tlaku. Úraz chir 11, 18-21.

16. McQueen, Gaston P, Court-Brown CM. (2000) Acute compartment syndrome. J Bone Surg 82-B, 200-203.

17. Michek J, Pleva L, Wendsche P. Poranění orgánů dutiny břišni a retroperitonea. Ostrava: Cicero, 1. vyd. 2001, 134.

18. Morris JA, Eddy VA, Blinman TA et al. (1993) The staged celiotomy for trauma. Ann Surg 217, 576-586.

19. Obeid F, Fath J, Guslits B et al. (1995) Increases in intraabdominal pressure affect pulmonary compliance. Arch Surg 130, 544-548.

20. Ridings PC, Bloomfeld GL, Blocher CR et al. (1995) Cardiopulmonaly effects of raised intra-abdominal pressure before and after intravascular volume expansion. J Trauma 39, 1071-1075.

21. Surgue M. (1995) Intra-abdominal pressure. Clin Intensiv Care 6, 76-79.

22. Zelenak $\mathbf{J}$ et al. (2003) Injuries of the intraabdominal organs at patients with polytrauma. Bratisl Lék Listy 104, 82-86. 